\title{
OJED
}

Volume 5, Issue 1 (2020), pp. 156-159

International Journal of

Multidisciplinary Perspectives in Higher Education

ISSN: 2474-2546 Print/ ISSN: 2474-2554 Online

https://ojed.org/jimphe

\section{Considering Karma: Reviving Student Agency Amid Pandemic Disempowerment}

\author{
Sue Erica Smith \\ Charles Darwin University, Darwin, Australia
}

\begin{abstract}
As pandemic lockdowns creep onwards to the end of 2020 many of my higher education students have become disempowered and despondent. In a bid to revive their agency and resilience a postgraduate class was offered this essay for critique. Karma is examined from contemporary understandings, and historical, and spiritual contexts, including some specifics from a Buddhist perspective where the intentions that impel actions become the prime determinants of resulting effects. Agentic attention to causality, interconnection and intention, endemic in global epistemologies, is presented as an empowering consideration regarding individual and collective activities to future researchers in the human sciences.
\end{abstract}

Keywords: agency; Buddhism; causality; karma; interconnection

My university is in the far north of Australia. The majority (70\%) of our students study online from urban, rural and remote localities across the country. The Australian academic year begins in March (when containment of the pandemic first became critical) and concludes in November (where movement across borders of states, even suburbs, and meeting people remains tightly contained). So, for the entire year's duration my students have been living and studying in various degrees of lockdown and social isolation. The year has been characterized by withdrawal: from courses, units, and (online) social engagement. My Master of Education Global Learning (MEDGL) Research Methods unit has seen Semester 1 
withdrawals up to $42 \%$ up from $23 \%$ in 2019 , and Semester 2 withdrawals at $50 \%$ up from $18 \%$ the previous year. Lockdown delivered quality assignments initially, study anchored and offered purpose, but now fatigue has set in. My students tell me they are exhausted. In the unit we explore philosophies and paradigms from global perspectives. I wrote the essay below as a primer for discussion, that might also offer potentiality to reassert agency, wellbeing and globally aware research.

\section{A synoptic overview of karma}

We live in a world where change is pervasive, constant and invariably dramatic. We also live in a world that is intrinsically interconnected, and it is from these two irrefutable principles that karma can be understood. They are experienced viscerally in this year of pandemic where we have isolated because of global connections - and have borne witness to life-changing events and anthropogenic environmental catastrophes. As we reel from these effects it becomes timely to consider what we can create. Keen attention to karma potentially offers means for empowerment, and a countermeasure to grief, loneliness and rage. While notions of karma are ubiquitous, 'What goes around comes around' highly reductive understanding has limited utility These partial understandings emphasize results of actions and are not particularly helpful. Karma is about cause and effect relationships. Looking closer into causality and what I/ we can do can provide a more productive way forward.

The word karma derives from the Sanskrit root $k r$ to do, and literally means 'action', 'doing', and describes a process. Karma remains an established pillar of Indic spiritualities: Hindu (both monistic and pantheistic schools), Jain, Sikh and Buddhist. The wisdom of interdependent causeeffect relationship is widespread, rooted in millennia, and remains a pluralistic theory. The seminal ancient Greek philosopher Heraclitus' legacy of fragmented aphorisms suggest interconnection, "it is wise to agree that all things are one" (DK B50) and flux, "On those who enter the same rivers, ever different waters flow" (DKB12). Although Greek philosophy took a monist trajectory thereafter, Heidegger and Nietzsche both looked back to Heraclitus to find richness in his abstruse fragments to justify an ontology for human-centered inquiry, process philosophy and ethical discernment (author, 2013). Observance of interdependent cause-effect relationships too are features of Indigenous Australian, and indigenous and eco-spiritualities generally (Yunkaporta, 2019). Definite effects of ignorant, hateful and desire-filled actions, as well as positive actions, is also germane throughout the Bible: Matthew 13: 3-8; in Job 4:8, Galatians 6:7, Proverbs 18:24, Acts 5:3, and the centrality of individual choice in Deuteronomy 30: 19-20 .

According to the Buddha a deep understanding of karma presents a key to living happier lives. His teachings (the Dharma) were premised on the recognition that dissatisfaction and suffering is pervasive in this causal 
world. Despite best efforts, happiness does not remain a constant lived experience for anybody. Myriad disappointments, irritations, outrages, highs, triumphs, successes and other vexations are inevitable. How these are navigated, and crucially how these types of results are created, and avoided, is where awareness of karma is astute. Karma awareness helps to reconcile multitudinous temporal individualities, with the vagaries of the world at large. "[T]he law of karma is not regarded as rigid and mechanical, but rather flexible, fluid and dynamic. Nevertheless there are relatively stable repeated patterns that arise from this collection of impersonal, everchanging and conditioned events or processes, that form what we regard as a person's 'character" (Harvey, 2000, p. 24). Basically, it is the same universal algorithm, with individual choice.

From a Dharma perspective, individual agency provides the determinant function. Explicitly, karma means only 'volitional action', not all action, but never solely the effect alone (Rahula, 1978). Motivations are the drivers behind activity, whether these be thoughts, words or body actions. Awareness of motivations creates acumen for choice, selfdetermination and integrity. Entertaining the notion that cause-effect relationship pertains to psychological terrains as it does to all the physical operations on the planet presents a dispassionate rationale for ethical activity. The time-span between motivation, action and result is rarely instantaneous, and other pervading conditions can add to the fuzziness. Nevertheless, the equation still stands. What goes around will come around. Hence, begin with mindful attention. While to rail against injustices might be right, if impelled by anger or hatred inner and outer disturbances are exacerbated.

Wisdom is required to skillfully negotiate the complex array of motivations, choices, conditions, and manifest or possible activities. According to the Dharma, wisdom is cultivated across three tiers: by thought, study, and deep insight knowledge developed through meditation. In this way, for any person who recognizes dissatisfaction in themselves and seeks peace and happiness, openness to karma is heuristic (Humphreys, 2013).

This worldview aims for holistic development through intellectual and emotional balance. Meditation is instrumental in the intellectual development and the cultivation of wisdom. Subsequent mindful awareness refined in the process can facilitate control and choice for ethical conduct. These by default allay propensity for negative repercussions and lead to more peaceful and happier experiences for self and others. The Dalai Lama explains, that given all beings are connected and generally share the same sorts of predicaments, what happens internally and in the external world is connected, and it is therefore possible to both observe and predict potential effects. From this reasoning compassion is not only justified, it is the only plausible response. "Once we have understood our own place, we can 
extend that understanding to others and thereby come to feel deep compassion" (Gyatso, 2000, p. 27). In this schema wisdom and compassion become meta-ethical values from which various other values, such as generosity, kindness, patience, honesty, are subsumed. Understanding karma provides a practical guide for realizing our 'best selves' and for positioning ourselves as social researchers in research with social benefit.

Karmic awareness is a call to assert human agency and Bandura's (2018) assessment (forethought, self-reactiveness and self-reflection) helps to clarify. '[F]orethought enables people to transcend the dictates of their immediate environment and to shape and regulate the present to realize desired futures' (p.130) and actions determined. Self-reflectiveness is a metacognitive capability whereby agents 'reflect on their efficacy to realize given challenges, the soundness of their thoughts and actions, their values, and the meaning and morality of their pursuits' (p.131). Bandura also recognizes that agency is individual, collective and cross-cultural. "Not only are cultures not monolithic entities, but they are no longer insular. Global connectivity is shrinking cross-cultural uniqueness. Successful functioning requires an agentic blend of the different modes of agency" (pp.131-132).

\section{Conclusion}

Lived experience through the pandemic, with concomitant societal and environmental upheavals, has affirmed our interconnectedness, and subsequent individual and collective responsibilities. Interconnection and causality, karma, provides scope to bridge perceived divisions across philosophies, religions, cultures and researcher positionality and to enrich ethical discussion and practice in higher education to better equip future researchers to respond to our time.

\section{References}

Bandura, A. (2018). Toward a psychology of human agency: Pathways and reflections. Perspectives on Psychological Science, 13(2), 130-136.

Gyatso, T. (2000). The Meaning of Life: Buddhist perspectives on cause and effect (J. Hopkins, Trans. revised ed.).

Humphreys, C. (2013). The wisdom of Buddhism. Routledge.

Smith, S. E. (2013). Buddhist voices in school: How a community created a Buddhist education program for state schools. Springer Science \& Business Media.

Yunkaporta, T. (2019). Sand talk: How Indigenous thinking can save the world. Text Publishing. 